3. Deshar A., Gyanendra K., Lopsang Z. (2019) "MRI in the characterization of seminomatous and nonseminomatous germ cell tumors of the testis". International Journal of Science Inventions Today, $8(2), 411-419$.

4. Kim S.H., Cho J.Y. (2016) Oncologic imaging: urology, Springer, 169-197.

5. Lebastchi A.H., Watson M.J., Russell C.M., et al. (2018) "Using Imaging to Predict Treatment Response in Genitourinary Malignancies". Eur Urol Focus, 4 (6), 804-817.

6. Liu R., Lei Z., Li A., et al. (2019) "Differentiation of testicular seminoma and nonseminomatous germ cell tumor on magnetic resonance imaging". Medicine (Baltimore), 98 (45), e17937.

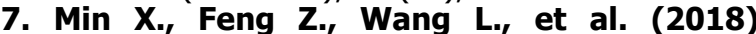
"Characterization of testicular germ cell tumors: Whole-lesion histogram analysis of the apparent diffusion coefficient at 3T". Eur J Radiol, 98, 25-31.

8. Partin A.W., Wein A.J., Kavoussi L.R., et al. (2020) Neoplasms of the Testis. Campbell Walsh Wein Urology. 12 ed. Elsevier Health Sciences,

9. Tsili A.C., Tsampoulas C., Giannakopoulos X., et al. (2007) "MRI in the histologic characterization of testicular neoplasms". AJR Am J Roentgenol, 189 (6), W331-7.

\title{
NGHIÊN CỨU ĐẶC ĐIỂM LÂM SÀNG VÀ NỒNG Độ DOPAMIN HUYẾT TƯO'NG Ở BỆNH NHÂN TÂM THẦN PHÂN LIỆT
}

\section{TÓM TẮT}

Mục tiêu: Đặc điểm lâm sàng và nồng độ dopamine huyết tương ở bệnh nhân tâm thần phân liệt. Đối tượng và phướng pháp nghiên cứu: Nghiên cứu mô tả, cắt ngang đặc điểm lâm sàng và nồng độ dopamine huyết tương ở 72 bệnh nhân tâm thân phân liệt điều trị nội trú taii khoa Tầm thân-Bênh viên Quân y 103 từ tháng 8/2020 đến tháng 1/2021. Kết quả: Nhóm tuổi thường găp từ 21-30 tuổi chiếm $37,5 \%$; nam $58,33 \%$; nữ $41,67 \%$; thể paranoid chiếm $87,50 \%$. Bênh nhân có 1 hoăc nhiêu loai ảo thanh chiếm $83,33 \%$, ảo thanh bình phẩm $(66,67 \%)$, ảo thanh đàm thoai $(61,67 \%)$. Bênh nhân có 1 hoăc nhiều loại hoang tưởng chiếm 94,44\%, hoang tưởng bi hai $(76,47 \%)$, hoang tưởng bi theo dõi $(51,47 \%)$. Các triệu chứng hay gặp: lười lao động và học tập $(86,11 \%)$, cảm xúc bùng nổ $(72,22 \%)$, giảm trí nhớ $(81,94 \%)$, tư duy nhịp chậm, ngắt quãng $(77,78 \%)$. Nồng độ dopamine huyết tương trung bình lần 1 của bệnh nhân $73,09 \pm 40,83 \mathrm{pg} / \mathrm{ml}$, nông độ dopamine huyết tương trung bình lân 2 của bệnh nhân là $27,91 \pm 19,13 \mathrm{pg} / \mathrm{ml}$ và nồng độ dopamine huyết tương trung bình nhóm chứng $26,55 \pm 12,32 \mathrm{pg} / \mathrm{ml}$. Sự khác biệt nồng độ dopamine huyết tương giữa xét nghiệm lần thứ 1 và lần thứ 2 ; giữa xét nghiệm lần thứ 1 và nhóm chứng có ý nghĩa thống kê; sự khác biệt giữa xét nghiệm lần thứ 2 và nhóm chứng không có ý nghĩa thổng kê. Kết luâan: Bệnh tâm thần phân liệt thường gặp ở lứa tuổi từ 21-30, không khác biệt về giới. Các biểu hiện chủ yếu là ảo thanh, hoang tưởng, rối loạn cảm xúc, rối loạn chú ý-trí nhớ, rối loạn hình thức tư duy. Nồng độ dopamine huyết tương trung bình của bệnh nhân tâm thân phân liệt cao hơn so với

\footnotetext{
*Bệnh viện Tâm thần Ban ngày Mai Hương **Bênh viện Quân y 103

Chịu trách nhiệm chính: Bùi Phương Thảo

Email: lolita.herb@gmail.com

Ngày nhận bài: 16.8.2021

Ngày phản biên khoa hoc: 8.10.2021

Ngày duyệt bài: 18.10 .2021
}

Bùi Phương Thảo*, Đỗ Xuân Tĩnh**

nhóm chứng và giảm về mức bình thường sau khi điều trị 3 tuần.

Tư khóa: Tâm thân phân liệt, đặc điểm lâm sàng, dopamin huyết tương.

\section{SUMMARY \\ RESEARCH FOR CLINICAL CHARACTERISTICS AND PLASMA DOPAMINE CONCENTRATIONS IN SCHIZOOPHRENIC PATIENTS}

Objectives: Clinical characteristics and plasma dopamine levels in schizophrenic patients. Subjects and Metholds: Descriptive reaserch, cross-sectional; clinical characteristics and plasma dopamine levels in 72 patients with schizophrenic inpatient were treated at the Department of Psychiatry - Military Hospital 103 from August 2020 to January 2021. Results: Common age group is from $21-30$ years old accounting for $37.5 \%$; male $58.33 \%$; female $41.67 \%$. Schizophrenia is a paranoid, accounting for $87,50 \%$. There are 1 or more types of auditory hallucination in schizophrenic patients, accounting for 83,33\%, commentary auditory $(66,67 \%)$, auditory hallucination as a conversion symptom $(61.67 \%)$. There are 1 or more types of paranoia in schizophrenic patients accounting for $94,44 \%$, paranoia of being harmed $(76,47 \%)$, paranoia of being spying on $(51,47 \%)$. Common symptoms: lazy in work and study $(86,11 \%)$ emotional explosion (72,22\%), forgetfulness $(81.94 \%)$, slow-paced thinking, intermittently thinking $(77,78 \%)$. The mean plasma dopamine concentration of the patient 1 st time was $73,09 \pm 40,83 \mathrm{pg} / \mathrm{ml}$, the mean plasma dopamine concentration of the patient 2nd time was $27,91 \pm 19,13 \mathrm{pg} / \mathrm{ml}$ and the mean plasma dopamine concentration of the control group was $26,55 \pm 12,32 \mathrm{pg} / \mathrm{ml}$. The difference in plasma dopamine concentration between the 1st and 2nd test; between the first test and the control group was statistically significant; The difference between the second test and the control group was not statistically significant. Conclusion: Schizophrenia is most common in people aged 21-30 years, no difference in gender. The main manifestations are auditory 
hallucinations, paranoia, emotional disturbances, attention-memory disorders, and thought-form disorders. The mean plasma dopamine concentration of patients with schizophrenia was higher than that of the control group and decreased to normal after 3 weeks of treatment.

Keywords: Schizophrenia, clinical features, plasma dopamine.

\section{I. ĐẶT VẤN ĐỀ}

Tâm thần phân liệt (Schizophrenia) là một bệnh loạn thần nặng và phổ biến. Bệnh đa số khởi phát ở lứa tuổi trẻ, do vậy ảnh hưởng rất lớn đến khả năng lao động và học tập của bệnh nhân. Người bệnh mất dần các chức năng nghề nghiệp, xã hội và trở thành gánh nặng cho bản thân, gia đình và xã hội. Triệu chứng của tâm thần phân liệt rất đa dạng và phong phú, bao gồm các triệu chứng rối loạn về tri giác, tư duy, cảm xúc, hành vi... Bệnh sinh của tâm thần phân liệt, đến nay vẫn chưa hoàn toàn rõ ràng. Theo nhiêu nhà tâm thần học, trong tâm thần phân liệt có sự tăng hoạt động của hệ dopaminergic và nồng độ dopamin trong dịch nã̃o tuỷ và trong huyết tương tăng cao. Khi các triệu chứng loạn thần được điều trị ổn định bằng thuốc an thẩn thì nồng độ của dopamin trong dịch não tuỷ và trong huyết tương sẽ trở lại bình thường [1].

Xuất phát từ những lý do trên, chúng tôi tiến hành nghiên cứu "đặc điểm lâm sàng và nồng độ dopamin huyêt tương ở bệnh nhân tâm thần phân liệt".

\section{II. ĐỐI TƯợNG VÀ PHƯƠ'NG PHÁP NGHIÊN CỨU}

2.1. Đối tượng nghiên cứu. 72 bệnh nhân tâm thần phân liệt (42 nam và 30 nữ) được chẩn đoán là theo tiêu chuẩn của ICD-10 (1992). Các bệnh nhân này được điều trị nội trú tại khoa Tâm thần-Bệnh viện Quân y 103 từ tháng 8/2020 đến tháng 1/2021. Tất cả các bệnh nhân đều được khám lâm sàng và lấy máu xét nghiệm nồng độ.

\subsection{Phương pháp nghiên cứu}

Phương pháp nghiên cứu: tiến cứu, cắt ngang có mô tả chi tiết từng trường hợp. Bệnh nhân được lấy máu định lượng dopamin huyết tương 2 lần: lần 1 từ 1-3 ngày sau khi vào viện, lần 2 cách 20 ngày sau khi vào viện. Định lượng nồng độ dopamin huyết tương theo phương pháp sắc ký lỏng tại khoa Sinh lý bệnh, Học viện Quân Y.

Xử lý số liệu bằng phần mềm SPSS 22.

\section{KẾT QUẢ NGHIÊN CỨU VÀ BÀN LUÂN}

Bảng 1. Thể bệnh của bệnh nhân tâm thân phân liệt

\begin{tabular}{|c|c|c|}
\hline Thể bệnh Chỉ số thống kê & $\begin{array}{l}\text { Số BN } \\
(n=72)\end{array}$ & $\begin{array}{c}\text { Tỷ lệ } \\
\%\end{array}$ \\
\hline Paranoid & 63 & 87,50 \\
\hline Thanh xuân & 2 & 2,78 \\
\hline Căng trương lực & 2 & 2,78 \\
\hline Di chứng & 5 & 6,94 \\
\hline Cộng & 72 & 100 \\
\hline
\end{tabular}

Theo Trịnh Văn Anh (2017), thể tâm thần phân liệt có hành vi tự sát chỉ gặp ở 3 thể trong nhóm đối tượng nghiển cứu, trong đó tâm thần phân liệt thể paranoid chiểm tỷ lệ cao hơn cả $(89,39 \%)$ [2].

Như vậy, dù tỷ lệ không hoàn toàn giống nhau giữa các nghiên cứu, nhưng đều thống nhất tỳ lệ tâm thần phân liệt cao nhất gặp ở thể paranoid các thể khác chỉ chiếm tỷ lệ nhỏ.

Bảng 2. Các loại ảo thanh

\begin{tabular}{|c|c|c|c|c|c|}
\hline \multirow{2}{*}{ Ảo thanh } & \multicolumn{2}{c|}{ Lần 1 số thống kế } & \multicolumn{2}{c|}{ Lần 2 } & \multirow{2}{*}{ p } \\
\cline { 2 - 6 } & Số BN (n=60) & Tỉ lệ \% & Số BN (n=60) & Tỉ lệ \%o & \\
\hline Bình phấm & 40 & 66,67 & 4 & 6,67 & $<0,001$ \\
\hline De doạ & 12 & 20,0 & 1 & 1,67 & $<0,001$ \\
\hline Đàm thoại & 37 & 61,67 & 1 & 1,67 & $<0,001$ \\
\hline Xui khiên & 24 & 40,0 & 1 & 1,67 & $<0,001$ \\
\hline Tư duy vang thành tiếng & 21 & 35,0 & 2 & 3,33 & $<0,001$ \\
\hline
\end{tabular}

Trong nghiên cứu của chúng tôi, có $83,33 \%$ bệnh nhân tâm thần phân liệt có một hoặc nhiều loại ảo thanh. Chúng đều hết sau 3-4 tuần điều trị.

Theo Trịnh Văn Anh (2017), số bệnh nhân có ảo giác chiếm 89,39\% nhóm nghiên cứu, triệu chứng ảo thanh bình phẩm $(51,51 \%)$, ảo thanh đe dọa $(21,21 \%)$, và ảo thanh xui khiến $(30,30 \%)$. Các triệu chứng này giảm nhanh sau khi điêu trị [2].

Như vậy, kết quả của chúng tôi tương đồng với hầu hết các tác giả khác khi nhận thấy ảo thanh là ảo giác hay gặp nhất và ảo thanh bình phẩm là phổ biến nhất trong các loại ảo thanh.

\section{Bảng 3. Các loại hoang tưởng của bệnh nhân tâm thân phân liệt}

\begin{tabular}{|c|c|c|c|c|c|}
\hline Chỉ số thống kê & Lần 1 & & Lần 2 & & \\
\hline Loại hoang tướng & Số BN $(n=68)$ & Tỉ lệ (\%) & Số BN $(n=68)$ & Tỉ lệ (\%) & p \\
\hline Hoang tưởng liên hệ & 28 & 41,18 & 1 & 1,47 & $<0,001$ \\
\hline
\end{tabular}


VIETNAM MEDICAL JOURNAL N² - NOVEMBER - 2021

\begin{tabular}{|c|c|c|c|c|c|}
\hline Hoang tưởng bị hại & 52 & 76,47 & 5 & 7,35 & $<0,001$ \\
\hline Hoang tưởng bị theo dõi & 35 & 51,47 & 2 & 2,94 & $<0,001$ \\
\hline Tư duy bị bộc lộ & 16 & 23,52 & 0 & 0 & \\
\hline Hoang tướng kỳ quái & 7 & 10,29 & 1 & 1,5 & $<0,05$ \\
\hline Hoang tưởng khác & 15 & 22,05 & 2 & 2,9 & $<0,001$ \\
\hline
\end{tabular}

Hoang tưởng là một triệu chứng phố biến trong tâm thân phân liệt. Trong nghiên cứu của chúng tôi có $94,44 \%$ bệnh nhân tâm thần phân liệt có một hoặc nhiều loại hoang tưởng. Các loại hoang tưởng khá phong phú và đều đáp ứng điều trị tương đối tốt, chúng đều hết sau 3-4 tuân điều trị.

Kết quả nghiên cứu của chúng tôi cũng phù hợp với Trịnh Văn Anh (2017) với hoang tưởng bị hại (72,73\%). [2].

Bảng 4. Rôi loạn chú ý và trí nhớ của bệnh nhân tâm thân phân liệt

\begin{tabular}{|c|c|c|c|c|c|}
\hline \multirow{2}{*}{ Rối loạn chú ý, trí nhớ } & \multicolumn{2}{|c|}{ Lân 1} & \multicolumn{2}{|c|}{ Lân 2} & \multirow[b]{2}{*}{$\mathbf{p}$} \\
\hline & $\begin{array}{c}\text { Số BN } \\
(n=72)\end{array}$ & $\begin{array}{l}\text { Tỉ lệ } \\
(\%)\end{array}$ & $\begin{array}{c}\text { Số BN } \\
(n=72)\end{array}$ & $\begin{array}{l}\text { Tỉ lệ } \\
(\%)\end{array}$ & \\
\hline Giảm tập trung chú ý & 49 & 68,06 & 2 & 2,78 & \\
\hline Chóng mệt mỏi khi tập trung, chú ý & 67 & 93,06 & 18 & 25,0 & 1 \\
\hline Giảm trí nhớ & 59 & 81,94 & 43 & 59,72 & $<0,05$ \\
\hline
\end{tabular}

Khi so sánh giữa 2 lần điêuu trị các triệu chứng rối loạn chú ý và trí nhớ có sự thuyên giảm. Số liệu của chúng tôi phù hợp với tác giả Trịnh Văn Anh (2017) [2].

Theo Sadock B.J. (2008), trí nhớ của bệnh nhân tâm thân phân liệt còn nguyên vẹn nhưng có thể có khiếm khuyết về nhận thức. Bềnh nhân tâm thân phân liệt biểu hiện rối loạn chức năng

nhận thức tinh vi trong các lĩnh vực chú ý, chức năng điêu hành, suy giảm trí nhớ. Sự suy giảm nhận thức này sẽ giảm đi khi bệnh nhân hết loạn thần [1].

Kết quả của chúng tôi phù hợp với nhận định trên. Khi các triêuu chứng loạn thân, trầm cảm thuyên giảm sau điều trị thì rối loạn chú ý và trí nhớ sẽ thuyên giảm theo.

Bảng 6. Các triệu chứng rôi loạn cảm xúc trên bệnh nhân tâm thân phân liệt

\begin{tabular}{|c|c|c|c|c|c|}
\hline \multirow{2}{*}{ Triêu chứng $\quad$ Chỉ số thống kê } & \multicolumn{2}{|c|}{ Lân 1} & \multicolumn{2}{|c|}{ Lân 2} & \multirow[b]{2}{*}{ p } \\
\hline & $\begin{array}{c}\text { Số BN } \\
(n=72)\end{array}$ & $\begin{array}{l}\text { Tỉ lệ } \\
(\%)\end{array}$ & $\begin{array}{c}\text { Số BN } \\
(n=72)\end{array}$ & $\begin{array}{l}\text { Tỉ lệ } \\
(\%)\end{array}$ & \\
\hline Giảm khí sắc & 20 & 27,78 & 6 & 8,33 & $<0,05$ \\
\hline Khí sắc kích thích và khí sắc tăng & 39 & 54,17 & 4 & 5,56 & $<0,001$ \\
\hline Hoang mang, lo lắng & 43 & 59,72 & 2 & 2,78 & $<0,001$ \\
\hline Cảm xúc bùng nố & 52 & 72,22 & 2 & 2,78 & $<0,001$ \\
\hline Cảm xúc không thích hợp & 27 & 37,5 & 2 & 2,78 & $<0,001$ \\
\hline Cảm xúc cùn mòn & 23 & 31,94 & 20 & 27,78 & $>0,05$ \\
\hline Mất ngủ & 60 & 83,33 & 0 & 0 & \\
\hline Giảm nhận thức với công việc & 58 & 80,56 & 38 & 52,78 & $<0,001$ \\
\hline Cách ly xã hội & 57 & 79,17 & 26 & 36,11 & $<0,001$ \\
\hline Vệ sinh cá nhân kém & 39 & 54,17 & 25 & 34,72 & $<0,001$ \\
\hline Không quan tâm chăm sóc bản thân & 50 & 69,44 & 20 & 27,78 & $<0,001$ \\
\hline Lười lao động và học tập & 62 & 86,11 & 29 & 40,28 & $<0,001$ \\
\hline
\end{tabular}

Các triệu chứng rối loạn cảm xúc và lo âu là hay gặp ở bệnh nhân tâm thân phân liệt. Bệnh nhân hay có triệu chứng giống với pha trầm cảm, nhưng cũng có thể có triệu chứng giống pha hưng cảm. Các triệu chứng này không nổi bật trên lâm sàng nên dế bị bỏ qua.

Trong bệnh tâm thân phân liệt, các rối cảm xúc của bệnh nhân là hậu quả của hàng loạt các triệu chứng dương tính (hoang tưởng, ảo giác) và âm tính (cảm xúc cùn mòn, mất ý chí, ngôn ngữ nghèo nàn). Nghiên cứu của chúng tôi đã phản ánh rõ nhận định này. Bên cạnh đó, hâu hết bênh nhân tâm thân phân liệt đều có rối loạn giấc ngủ.

Khi so sánh các triệu chứng rối loạn cảm xúc trên nhóm bệnh nhân nghiên cứu tại 2 thời điểm thăm khám thấy sự khác biệt có ý nghĩa thống kê với $\mathrm{p}<0,05$. Kết quả này phù hợp với nhận định rối loạn cảm xúc của bệnh nhân là do các triệu chứng loạn thân chi phối và sẽ hết khi các triệu chứng này được điêu trị bằng thuốc an thẩn mới.

Kết quả của chúng tôi cũng phù hợp với Trịnh Văn Anh (2017) và Nguyễn Thanh Bình (2010) [2], [3]. 
Bảng 7. Các loại rối loạn hình thức tư duy trên bệnh nhân tâm thần phân liệt

\begin{tabular}{|c|c|c|c|c|c|}
\hline \multirow{2}{*}{ Triệu chứng Chỉ số thống kề } & \multicolumn{2}{|c|}{ Lần 1 } & \multicolumn{2}{|c|}{ Lần 2 } & \multirow{2}{*}{$\mathbf{~}$} \\
\cline { 2 - 6 } & $\mathbf{( n = 7 2 )}$ & Tỉ lệ (\%) & $\mathbf{( n = 7 2 )}$ & Tỉ lệ (\%) & p \\
\hline Tư duy nhịp chậm, ngắt quãng & 56 & 77,78 & 35 & 48,61 & $\mathrm{p}<0,001$ \\
\hline Tư duy lai nhai & 22 & 30,56 & 7 & 9,72 & $\mathrm{p}<0,001$ \\
\hline Nói một mình & 41 & 56,94 & 3 & 4,17 & $\mathrm{p}<0,001$ \\
\hline Tư duy không liên quan & 22 & 30,56 & 2 & 2,78 & $\mathrm{p}<0,001$ \\
\hline Kích động ngôn ngữ & 31 & 43,06 & 1 & 1,39 & $\mathrm{p}<0,001$ \\
\hline
\end{tabular}

Trong nghiên cứu của chúng tôi, các triệu chứng rối loạn hình thức tư duy khá phổ biến và đa dạng. Khi so sánh các nhóm số liệu giữa 2 lần khám thấy sự khác biệt có ý nghĩa thống kê với $\mathrm{p}<0,001$.

Nghiên cứu của chúng tôi có kết quả phù hợp với kết quả của Nguyễn Thanh Bình (2010) và Trịnh Văn Anh (2017) [2], [3].

Tác giả Sadock B.J. (2008) cũng nhấn mạnh đến rối loạn hình thức tư duy biểu hiện trong cách nói và viết của bệnh nhân đặc biệt khi họ thực hiện các công việc rời rạc. Rối loạn này bao gồm bùng nổ ý tưởng, tư duy không liên quan, tư duy lai nhai, tư duy ngắt quãng, không tập trung chú ý, tư duy nghèo nàn. [1].

Bảng 8. Nồng độ dopamine huyêt tương ở các đôi tượng nghiên cứu

\begin{tabular}{|c|c|c|c|c|c|c|}
\hline Kết quả Chỉ số & $\mathbf{n}$ & $\begin{array}{c}\mathbf{X} \\
(\mathrm{pg} / \mathrm{ml})\end{array}$ & $\begin{array}{c}\mathbf{C L} \\
(\mathrm{pg} / \mathrm{ml})\end{array}$ & $\begin{array}{l}\text { SD } \\
(\mathrm{pg} / \mathrm{ml})\end{array}$ & $\begin{array}{l}\text { Median } \\
(\mathrm{pg} / \mathrm{ml})\end{array}$ & $\begin{array}{c}\mathbf{S E} \\
(\mathrm{pg} / \mathrm{ml})\end{array}$ \\
\hline XN lần 1 & 72 & 73,09 & $73,09 \pm 40,83$ & 40,83 & 66,52 & 4,81 \\
\hline XN lần 2 & 72 & 27,91 & $27,91 \pm 19,13$ & 19,13 & 22,93 & 2,25 \\
\hline XN nhóm chứng & 32 & 26,55 & $26,55 \pm 12,32$ & 12,32 & 26,55 & 2,18 \\
\hline \multicolumn{2}{|l|}{$\mathrm{p}_{1-3}$} & & \multicolumn{4}{|c|}{$<0,001\left(\mathrm{t}_{1-3}=9,67\right)$} \\
\hline \multicolumn{2}{|l|}{$p_{2-3}$} & & \multicolumn{4}{|c|}{$>0,5\left(t_{2-3}=0,60\right)$} \\
\hline \multicolumn{2}{|l|}{$p_{1-2}$} & & \multicolumn{4}{|c|}{$<\mathbf{0 , 0 0 1}\left(\mathrm{t}_{2-3}=10,12\right)$} \\
\hline
\end{tabular}

Kết quả nghiên cứu cho thấy tại lần xét nghiệm thứ 1 , khi bệnh nhân đang có nhiều triệu chứng rầm rộ, nồng độ dopamine huyết tương rất cao. Sự khác biệt về nồng độ dopamine huyết tương lần xét nghiệm 1 với nhóm chứng là có ý nghĩa thống kê với $p<0,001$. Sau khi điều trị từ 3-4 tuần, các triệu chứng đã thuyên giảm, nồng độ dopamin huyết tương giảm rõ rệt ở lần xét nghiệm thứ 2. Sự khác biệt về nồng độ dopamine huyết tương giữa 2 lần xét nghiệm có ý nghĩa thống kê. Tuy nhiên, tại lần xét nghiệm 2 và nhóm chứng, sự khác biệt là không có ý nghĩa thống kê

Điều này phù hợp với các tác giả Rao M.L. (1993), đã định lượng dopamin trong huyết tương, dịch não tủy của bệnh nhân tâm thần phân liệt. Tác giả nhận thấy nống độ dopamin huyết tương tăng cao ở bệnh nhân tâm thần phân liệt so với người bình thường và giảm rõ rệt sau khi điều trị [4].

Kết quả của chúng tôi có kết luận tương đồng với Nguyễn Thanh Bình (2010) khi cho rằng trước điêu trị, nồng độ dopamine huyết tương cao ở bệnh nhân tâm thần phân liệt so với người bình thường, khi các triệu chứng thuyên giảm dưới tác dụng điều trị của thuốc an thần thì nồng độ dopamine cũng dần giảm về mức bình thường. Tuy nhiên về nồng độ trung bình huyết tương trong nghiên cứu của chúng tôi và Nguyễn Thanh Bình khác nhau do Nguyễn Thanh Bình sử dụng phương pháp ELISA [5].

Nồng độ dopamine huyết tương là thước đo đáng tin cậy để đánh giá kết quả điều trị. Các tác giả Dávila R. (2007) và Z.J. Zhang (2000) nhận định rằng định lượng nồng độ dopamin huyết tương có ý nghĩa đánh giá kết quả điều trị cả với triệu chứng dương tính lẫn âm tính [5], [6].

\section{KẾT LUÂN}

- Tâm thần phân liệt là thể paranoid chiếm tỷ lệ $87,50 \%$.

- Các bệnh nhân có 1 hoặc nhiều loại ảo thanh chiếm $83,33 \%$, ảo thanh bình phẩm $(66,67 \%)$, ảo thanh đàm thoại $(61,67 \%)$.

- Các bệnh nhân có 1 hoặc nhiêu loại hoang tưởng chiếm $94,44 \%$, hoang tưởng bị hại $(76,47 \%)$, hoang tưởng bị theo dõi $(51,47 \%)$.

- Các triệu chứng hay gặp: Cách ly xã hội (79,17\%), lười lao động và học tập $(86,11 \%)$, cảm xúc bùng nổ $(72,22 \%)$, giảm trí nhớ $(81,94 \%)$, tư duy nhịp chậm, ngắt quãng $(77,78 \%)$.

- Nồng độ dopamine huyết tương trung bình lần 1 của bệnh nhân $73,09 \pm 40,83$ pg/ml, nồng độ dopamine huyết tương trung bình lần 2 của bệnh nhân là $27,91 \pm 19,13 \mathrm{pg} / \mathrm{ml}$ và nồng độ dopamine huyết tương trung bình nhóm chứng $26,55 \pm 12,32 \mathrm{pg} / \mathrm{ml}$. 
- Sự khác biệt nồng độ dopamine huyết tương giữa xét nghiệm lần thứ 1 và lần thứ 2; giữa xét nghiệm lần thứ 1 và nhóm chứng có ý nghĩa thống kề với; sự khác biệt giữa xét nghiệm lần thứ 2 và nhóm chứng không có ý nghĩa thống kê.

\section{TÀI LIÊU THAM KHẢO}

1. Sadock B.J., Sadock V.A. (2008). "Schizophrenia", Concise textbook of clinical psychiatry, Third edition, William and Wilkins, pp. 156-177.

2. Trinh Văn Anh (2017). Nghiên cứu đăc điểm dich tể học lâm sàng rối loạn tâm thân ở bệnh nhân tự sát. Luạân án tiến sỹ, Học viện Quân Y, Hà Nội.

3. Nguyển Thanh Bình (2010). Nghiên cứu đặc điểm lâm sàng và nồng độ Dopamine huyết tương ở bệnh nhân tâm thần phẩn liệt thể paranoid. Luận án tiến sỹ, Học viện Quân Y, Hà Nội.

4. Rao M.L., Gross G., Halaris A. et al. (1993). "Hyperdopaminergia in schizophreniform psychosis: a chronobiological study", Psychiatry Res, May, 47(2), pp. 187-203.

5 . Dávila R., Zumárraga M., Basterreche N. et al. (2007). "Plasma homovanillic acid levels in schizophrenic patients: correlation with negative symptoms", Psychiatry Res., 30; 151(1-2), pp. 163-168.

6. Z.J.Zhang, M.Peet, C.N.Ramchand et al., (2001). "Plasma homovanillic acid in untreated schizophrenia - relationship with symptomatology and sex", Journal of Psychiatric Research, Volume 35 , Issue 1 , pp. 23-28.

\section{ĐÁNH GIÁ SỰ TUÂN THỦ SỬ DỰG THUỐC LEVOTHYROXINE Ở BỆNH NHÂN SUY GIÁP TIÊN PHÁT CAO TUỔI TẠI BỆNH VIỆN HỮU NGHI!}

\section{TÓM TẮT}

Mục tiêu: Xác định tỉ lệ tuân thủ sử dụng thuốc Levothyroxine (L-T4) và các yếu tố liên quan ở bệnh nhân suy giáp tiên phát (SGTP) cao tuổi tại phò̀ng khám Nội tiết, bệnh viện Hữu Nghị. Đối tượng và phương pháp nghiên cứu: nghiên cứu mổ tả cắt ngang trên 82 bênh nhân suy giáp tiên phát, tuổi từ 60 đến 87, tham gia khám bệnh tại phòng khám Nội tiết, bênh viên Hữu Nghi từ 8/2020 đến 8/2021. Các xét nghiệm được tiến hành gôm TSH, FT4. Kết quả và bàn İuân: Có $85,4 \%$ bênh nhân tuân thủ điều trị thuốc (TTĐTT). Mức độ TTĐTT: cao 69,5\%; trung bình 15,9\%; thấp $14,6 \%$. Có $78,1 \%$ đat muc tiêu điều trị (bình giáp), 21,9\% chưa đạt mục tiêu điều trị. Các yểu tố liên quan đến tỉ lê tuân thủ điều tri L-T4 là trình đô hoc vấn $(\mathrm{OR}=11,8 ; 95 \% \mathrm{CI}: 2,6-54,3)$ và muc tiểu điều trị (OR=4,8,95\% CI:1,3-17,6). Kết luân: Tỷ lệ tuân thủ sử dụng thuốc L-T4 trên bệnh nhân suy giáp tiên phát cao tuổi chiếm khoảng $85,4 \%$. Các yếu tố liên quan đến tuân thủ sử dụng thuốc L-T4: Trình độ học vấn và mục tiêu điều trị. Kiến nghị: hướng dẩn bệnh nhân tham khảo các tài liệu, sách báo, tạp trí, internet cùng sự hướng dẫn của nhân viên y tế về bênh suy giáp.

Tư khóa: Tuân thủ điều trị thuốc, suy giáp tiên phát, Levothyroxine.

\section{SUMMARY}

\footnotetext{
${ }^{1}$ Bệnh viện Hữu nghị

²Bênh viện Bach Mai,

${ }^{3}$ Trường đại hoc Y Hà Nôi

Chịu trách nhiệm chính: Phạm Thị Hằng

Email: minhhangpham87@gmail.com

Ngày nhận bài: 12.8.2021

Ngày phản biên khoa hoc: 8.10 .2021

Ngày duyệt bài: 14.10.2021
}

\author{
Phạm Thị Hằng ${ }^{1}$, Nguyễn Quang Bảy ${ }^{2,3}$
}

\section{ASSESSMENT OF COMPLIANCE WITH LEVOTHYROXINE IN ELDERLY PATIENTS WITH HYPOTHYROIDISM AT FRIENDSHIP HOSPITAL}

Objective: To determine the rate of adherence to using Levothyroxine (L-T4) and related factors in elderly patients with primary hypothyroidism at the Endocrinology clinic, Huu Nghi hospital. Subjects and methods: a cross-sectional descriptive study on 82 primary hypothyroidism patients, aged 60 to 87 years, who attended the medical examination at the Endocrine Clinic, Huu Nghi Hospital from August 2020 to August 2021. Tests were conducted including TSH, FT4. Results and discussion: $85.4 \%$ of patients adhered to drug treatment. Level of information communication: high 69.5\%; average $15.9 \%$; as low as $14.6 \%$. There were $78.1 \%$ reaching the treatment target (Euthyroid), 21.9\% not reaching the treatment goal. The factors related to the L-T4 adherence rate were education level $(\mathrm{OR}=11.8 ; 95 \% \mathrm{CI}$ : 2.6-54.3) and treatment goals $(\mathrm{OR}=4.8)$. , 95\% CI: 1.3-17.6). Conclusion: The rate of adherence to using L-T4 in elderly primary hypothyroidism patients is about $85.4 \%$. Factors related to adherence to L-T4 drug use: Education level and treatment goals. Recommendations: instruct patients to refer to documents, books, magazines, the internet and the guidance of medical staff about hypothyroidism.

Keywords: Drug adherence, primary hypothyroidism, Levothyroxine.

\section{I. ĐĂT VẤN ĐỀ}

Suy giáp(SG) là một trong những rối loạn nội tiết phố biến nhất, ảnh hưởng đến $10 \%$ dân số toàn câu[1]. Tại Việt Nam, bệnh SG khá thường gặp, tỷ lệ mắc bệnh này tăng theo tuổi. SG có nhiều nguyên nhân khác nhau và thường phải điều trị lâu dài. Nếu điều trị tốt thì chất lượng 